Soares, DR, Melo Neto, OM, Silva, GCB \& Aragão, R (2020). Estimation of the waterproofing degree of urban basins in the city of Campina Grande. Research, Society and Development, 9(7): 1-18, e479974377

\title{
Estimativa do grau de impermeabilização das bacias urbanas da Cidade de Campina
}

\section{Grande}

Estimation of the waterproofing degree of urban basins in the City of Campina Grande

Estimación del grado de impermeabilización de las cuenas urbanas en la Ciudad de Campina Grande

Recebido: 09/05/2020 | Revisado: 12/05/2020 | Aceito: 13/05/2020 | Publicado: 23/05/2020

Debora Rodrigues Soares

ORCID: http://orcid.org/0000-0003-1287-9297

Universidade Federal de Campina Grande, Brasil

E-mail: debora-r-s@ hotmail.com

Osires de Medeiros Melo Neto

ORCID: http://orcid.org/0000-0002-2535-0969

Universidade Federal de Campina Grande, Brasil

E-mail: osiresdemedeiros@gmail.com

Gustavo Correia Basto da Silva

ORCID: http://orcid.org/0000-0002-6081-2540

Universidade Estadual da Paraíba, Brasil

E-mail: gugacorreiaa@gmail.com

Ricardo de Aragão

ORCID: https://orcid.org/0000-0001-9937-3568

Universidade Federal de Campina Grande, Brasil

E-mail: ricardoaragao@yahoo.com

\section{Resumo}

A população mundial vem sofrendo um aumento substancial nas últimas décadas e uma das consequências é o crescimento na taxa de impermeabilização do solo, que pode, por consequência, trazer problemas graves como enchentes e inundações. Para evitar esses acontecimentos é necessário ter um sistema de drenagem de águas pluviais eficiente, o que pode ser conseguido conhecendo o provável volume/vazão devido a um evento de precipitação de grande intensidade. A presente pesquisa busca determinar o grau de 
impermeabilização do solo das bacias urbanas na cidade de Campina Grande - PB via geotecnologia. Os resultados mostraram que para as áreas centrais o grau de impermeabilização já atinge valores próximos dos $80 \%$ e nas bacias periféricas este índice tende a aumentar, uma vez que é para estas bacias que os novos conjuntos residências estão sendo implantados.

Palavras-chave: Impermeabilização de solo; Densidade habitacional; Drenagem urbana.

\begin{abstract}
The world population has undergone a substantial increase in the last decades and one of the consequences is the increase in the rate of soil waterproofing, which can, as a consequence, bring serious problems such as floods and floods. To avoid these events it is necessary to have an efficient rainwater drainage system, which can be achieved by knowing the probable volume / flow due to a high intensity precipitation event. This research seeks to determine the degree of soil waterproofing in urban basins in the city of Campina Grande - PB via geotechnology. The results showed that for the central areas the degree of waterproofing already reaches values close to $80 \%$ and in the peripheral basins this index tends to increase, since it is for these basins that the new housing complexes are being implemented.
\end{abstract}

Keywords: Soil waterproofing; Housing density; Urban drainage.

\title{
Resumen
}

Este estudio aborda el análisis de empresas rurales que muestran la importancia de la preservación del medio ambiente frente al desarrollo económico. El objetivo es analizar este escenario de relevancia ambiental en medio de los impactos negativos que pueden ocasionarse con el uso de tecnologías innovadoras y el manejo irresponsable de los recursos naturales, buscando alternativas sostenibles para cambiar este escenario. En cuanto a la metodología utilizada, utiliza el método de enfoque deductivo, los métodos de procedimiento interpretativo y dialéctico y las técnicas de investigación bibliográfica y documental. La presente investigación aclara una agricultura alternativa para reemplazar a la moderna, es decir, basada en mecanismos que reducen los impactos al medio ambiente $y$ se desarrollan económicamente.. Por lo tanto, concluye que, basándose en la aplicación de la sostenibilidad, las empresas rurales que utilizan mecanismos sostenibles en su proceso de producción pueden satisfacer las demandas mientras conservan el medio ambiente y aún se desarrollan económicamente, pudiendo ser aplicadas en las empresas rurales.

Palabras clave: Empresa rural; Agricultura sostenible; Desarrollo económico. 


\section{Introdução}

É inegável que, com o passar dos séculos, a população mundial sofreu um aumento exponencial, e no Brasil não foi diferente. Conforme o IBGE (2018), o país já tem aproximadamente 208.494.900 habitantes e para o ano de 2060, o Brasil terá 228.286.374 habitantes. Esse aumento populacional acarreta, diretamente, no aumento da urbanização, que pode trazer consigo graves consequências, como por exemplo, problemas relacionados a drenagem urbana, quando existente, ou à falta dela. Esta se mostra inadequada devido à falta de planejamento, além do constante aumento do grau de impermeabilização do solo, que possibilita a ocorrência de alagamentos, enchentes e inundações. Estes problemas são encontrados em diversas partes do Brasil, e em particular no Estado Paraíba, no nordeste brasileiro, onde, de acordo com o levantamento feito pelo IBGE, em 2012 a Paraíba tinha 3.766.528 habitantes, sendo, desse modo, detentora de aproximadamente 1,97\% da população brasileira. Desses, 385.213 habitantes $(0,19 \%)$ eram do município de Campina Grande, a segunda maior cidade deste Estado, também considerado polo educacional de serviços e industrial, onde vivem com $10 \%$ da população do estado. A mesma tem mais de $95 \%$ da sua população estabelecida na região urbana, onde foram registrados, nos últimos anos, vários pontos de inundação, causando transtorno à população, além de graves prejuízos econômicos.

A taxa de urbanização teve seu crescimento distribuído ao longo dos anos. De acordo com o IDEME (Instituto de Desenvolvimento Estadual e Municipal da Paraíba), a região de Campina Grande teve um crescimento do grau de urbanização de 68,55\% para 72,24\% entre os anos 2000 e 2010, entretanto, esses valores se referem a taxa de urbanização, e não ao grau de impermeabilização. Em relação ao grau de impermeabilização, os valores existentes são estimativas estatísticas que podem ser correlacionados diretamente com o grau de urbanização, assim, é possível perceber que o grau de impermeabilização do solo aumentou ao longo dos anos, mas não se sabe exatamente o quanto, até os dias atuais.

Em relação ao aumento da impermeabilização, essa está ligada ao maior escoamento superficial, o que pode vir a ser um problema de grande dimensão, relacionado a inundações e enxurradas, como o caso ocorrido na chuva do dia 09 de fevereiro de 2018, em Campina Grande. Para que haja diminuição desses impactos no meio e se evitem prejuízos à população, é obrigatória a realização de projetos de drenagem e conscientização ambiental. Assim, diante da necessidade da construção de um sistema drenante eficiente, surge a necessidade do conhecimento do grau de impermeabilização da bacia. Segundo Rufino et al. (2015) a aplicação do modelo hidrológico relacionado a drenagem urbana tem a necessidade de 
conhecimento da área impermeável e das modificações das condições de escoamento superficial provocadas pela ocupação do solo urbano.

Para se obter um resultado mais condizente com a verdadeira situação referente ao grau de impermeabilização do solo de Campina Grande, existem diversas técnicas, dentre elas o uso das geotecnologias, representadas via imagens de satélites de alta resolução e emprego conjunto de sistemas de informações geográficas. Estas técnicas tem sido utilizadas a considerável tempo, produzindo bons resultados que podem ser utilizados para o correto planejamento da drenagem urbana (Rufino et al., 2015; Aragão et al, 2017). Desse modo, a presente pesquisa busca determinar o grau de impermeabilização do solo das bacias urbanas na cidade de Campina Grande - PB via geotecnologia.

\section{Metodologia}

Uma pesquisa objetiva trazer novos conhecimentos e saberes à sociedade como preconiza Pereira et al. (2018). Quanto à metodologia, utiliza-se o método da abordagem dedutiva, os métodos de procedimento interpretativo e dialético e as técnicas de pesquisa bibliográfica e documental. O método de pesquisa utilizado envolveu o programa QGis e arquivos relativos aos bairros e bacias urbanas gerados por Tsuyuguchi (2015).

A Figura 1 apresenta imagens de satélite do Google Earth (Google, 2018), a fim de demonstrar quais bairros uma ou mais bacias poderiam englobar. Foram utilizadas, também, imagens de satélites, de alta resolução de Campina Grande para o ano de 2010, cedidas pela Secretaria de Planejamento de Campina Grande (SEPLAN). 
Figura 1 - Divisão dos bairros (em vermelho), das bacias (em azul) da cidade de Campina Grande.

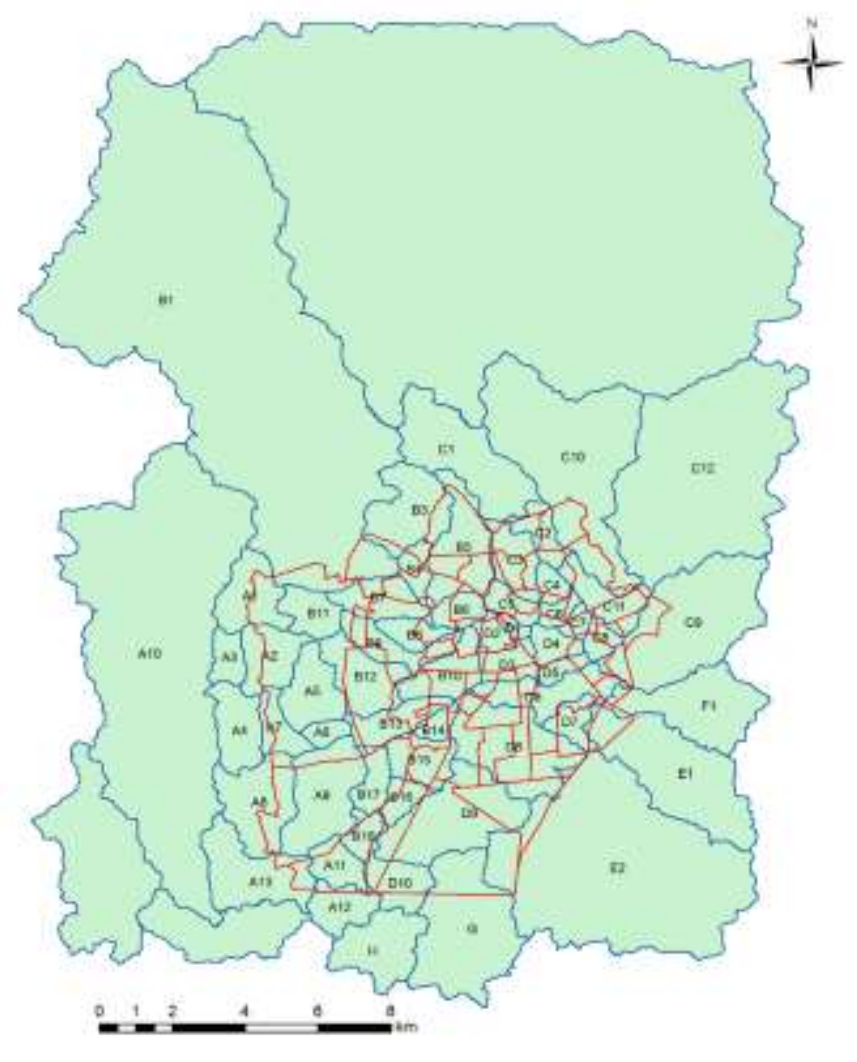

Fonte: Autores.

As imagens cedidas pela SEPLAN são de alta resolução da cidade de Campina Grande, de pixel 10x10 cm, juntamente com um mapa, no programa AutoCad, indicando a exata posição de cada uma das imagens. Essas, por sua vez, foram posicionadas em seus devidos locais, formando um mosaico de imagens, e recortados na forma das bacias urbanas de Campina Grande, e foi dada a nomeação com uma letra e um números para cada uma 14 das bacias formadas. A Tabela 1, representa todos os nomes das bacias e os bairros que cada bacia englobou: 
Research, Society and Development, v. 9, n. 7, e479974377, 2020

(CC BY 4.0) | ISSN 2525-3409 | DOI: http://dx.doi.org/10.33448/rsd-v9i7.4377

Tabela 1 - Bacias e bairros envolvidos.

\begin{tabular}{c|c}
\hline Bacia & Bairros envolvidos na bacia \\
\hline D8 & Jardim Quarenta, Liberdade, Jardim paulistano, Cruzeiro, Tambor, \\
& Catolé, Itararé, Sandra Cavalcante, Santa Rosa \\
\hline D7 & Sandra Cavalcante, Catolé, Vila Cabral \\
\hline D5 & Catolé, José Pinheiro \\
\hline D4 & Centro, José Pinheiro \\
\hline D3 & São José, Liberdade, Estação Velha, Centro, Centenário \\
\hline D2 & Prata, Bela Vista, Monte Santo, Centro \\
\hline C8 & José Pinheiro, Monte Castelo, Santo Antônio, Castelo Branco \\
\hline C7 & Lauritzen, Centro, Jardim Tavares, Alto Branco Pinheiro, Santo Antônio, Jardim Tavares \\
\hline C6 & Centro, Monte Santo, Palmeira, Conceição, Jeremias \\
\hline C5 & Alto Branco, Lauritzen, Conceição \\
\hline C4 & Jardim Continental, Alto Branco, Nações \\
\hline C2 & Santa Rosa, Centenário, Quarenta, Bela Vista, Prata \\
\hline B10 & Jeremias, Araxá, Cuité, Jardim Continental, Palmeira, Monte \\
B5 & Santo, Universitário \\
\hline
\end{tabular}

Fonte: Autores.

Após criar o mosaico das imagens relativas a cada bacia, foi efetuada a classificação supervisionada através da ferramenta Dzetsaka. A classificação será dividida em três itens, sendo eles: Árvores e descampados; Ruas asfaltadas e pavimentadas; Casas, prédios e construções.

Para melhor representatividade do conteúdo da imagem durante a classificação, foram colhidas "amostras" em cinco regiões diferentes da imagem, representando as classes antes citadas. Essa distribuição foi feita porque algumas partes das imagens são mais claras, indicando que a imagem foi obtida pelo satélite de manhã, e outras foram tiradas a tarde, alterando as cores dos pixels para um mesmo item, tornando necessário que, para um mesmo item, se tenha mais de uma amostra representativa.

A Figura 2 representa a bacia de contribuição para o açude velho, localizado no centro 
da cidade, que nesse trabalho recebeu o nome de D4 (Ver item 5, Tabela 1), é possível perceber que a região do lado extremo esquerdo é mais escura que a região centro-esquerda do mapa e também diferente da região direita, indicando que, dentro da mesma imagem da bacia, existem 3 cores de pixel diferentes para casas, asfaltos e árvores devido ao horário em que as imagens foram obtidas.

Figura 2 - Imagem da bacia D4 para exemplificação.

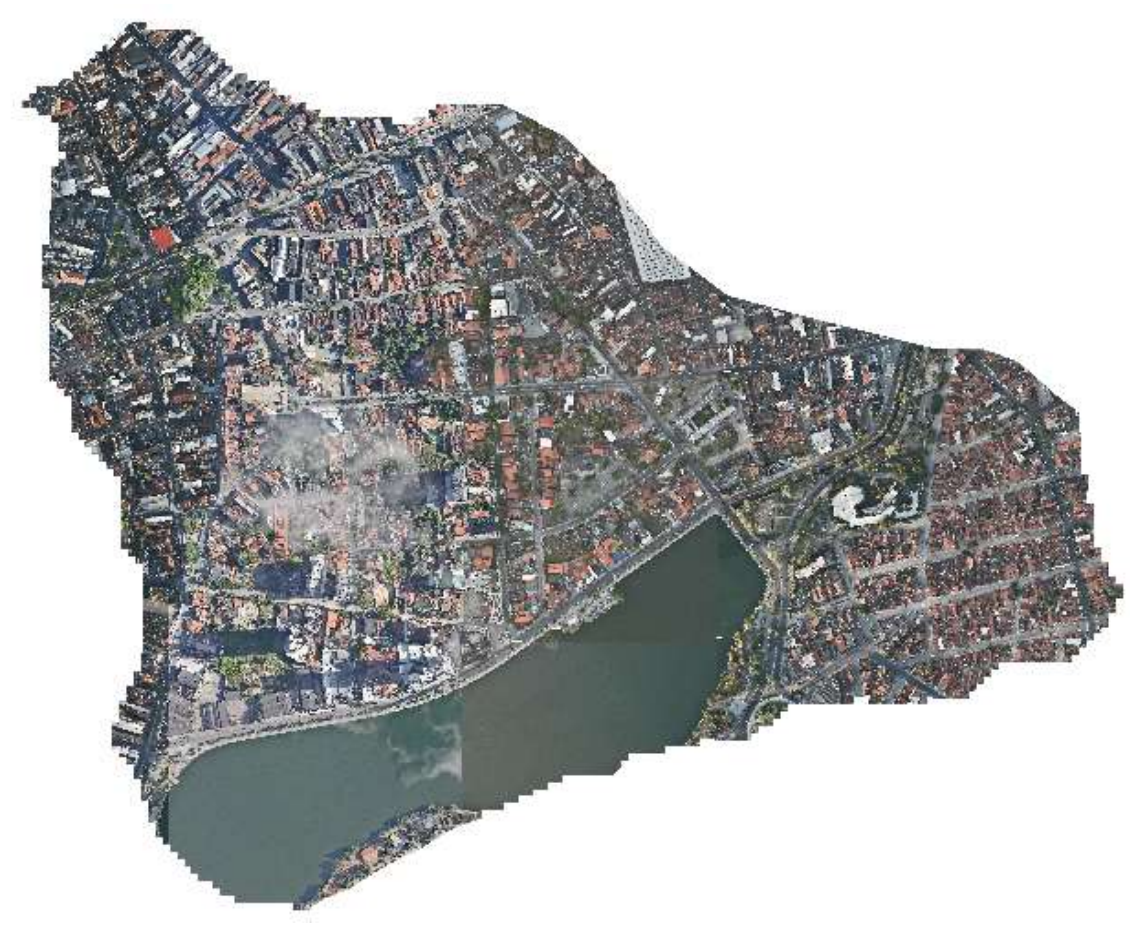

Fonte: Autores.

Para organização e melhor desenvolvimento do trabalho, a classificação foi feita com 15 amostras, sendo 6 amostras para árvores e descampados, 4 amostras para casas, prédios e construções e 5 amostras para ruas asfaltadas e pavimentadas. Essas amostras foram distribuídas em 5 regiões diferentes de cada uma das bacias urbanas, para que assim houvesse melhor aferição acerca da classificação. Em um dos casos foi acrescentada a décima sexta amostra.

Para regiões que continham grande quantidade de água, como na Figura 2, o item 14, onde seriam uma região de casas, prédios e construções, foi trocado para o item água, representando locais que possuem grande acumulo de água. No final, a troca de itens ocorrerá sem maiores interferências para os valores de permeabilidade, pois ambos representam áreas impermeáveis. A Tabela 2 apresenta a classificação por ordem de classe de uso, utilizada na obtenção das informações. 
Research, Society and Development, v. 9, n. 7, e479974377, 2020

(CC BY 4.0) | ISSN 2525-3409 | DOI: http://dx.doi.org/10.33448/rsd-v9i7.4377

Tabela 2 - Classes empregadas na classificação das imagens.

\begin{tabular}{c|l|c}
\hline $\mathbf{N}^{\circ}$ da classe & Tipo de classe & Referente a Região \\
\hline 1 & Árvores e descampados & 1 \\
\hline 2 & Ruas asfaltadas e pavimentadas & 1 \\
\hline 3 & Casas, prédios e construções & 2 \\
\hline 4 & Ruas asfaltadas e pavimentadas & 2 \\
\hline 5 & Casas, prédios e construções & 3 \\
\hline 6 & Árvores e descampados & 3 \\
\hline 7 & Ruas asfaltadas e pavimentadas & 4 \\
\hline 8 & Árvores e descampados & 4 \\
\hline 9 & Ruas asfaltadas e pavimentadas & 3 \\
\hline 10 & Árvores e descampados & 5 \\
\hline 11 & Casas, prédios e construções & 5 \\
\hline 12 & Ruas asfaltadas e pavimentadas & 4 \\
\hline 13 & Árvores e descampados & 5 \\
\hline 14 & Casas, prédios e construções (água) & 5 \\
\hline 15 & Árvores e descampados & 2 \\
\hline 16 & Casas, prédios e construções & 2 \\
\hline
\end{tabular}

Fonte: Autores.

Após toda a classificação, ainda no programa QGis, foram obtidas as áreas de cada uma das classes citadas acima, em quilômetros quadrados. Em seguida, foram somadas todas as áreas de uma mesma classe e sendo assim, obteve-se o valor da área permeável, e impermeável.

Depois foram calculados os coeficientes de escoamento da área permeável, obtido pela divisão da área permeável pela área total, e o coeficiente de área impermeável, obtido pela divisão da área permeável pela área total. Assim foi possível obter o grau de impermeabilização mais recente da cidade, dado pela Equação 1:

$$
C=\frac{c_{p} A_{p}+C_{i} A_{i}}{A_{t}}
$$

No qual Cp é o coeficiente de escoamento da área permeável da bacia; Ap é a área permeável da bacia $\left(\mathrm{km}^{2}\right)$; Ci é o coeficiente de escoamento da área impermeável; Ai é a área impermeável da bacia $\left(\mathrm{km}^{2}\right)$. 
Após obtidos os valores de $\mathrm{C}$ pela Equação 1, foi feita a porcentagem de área impermeável (AI) para cada uma das bacias, dividindo a área impermeável pela área total em valor percentual. Em seguida os valores de $\mathrm{C}$ e AI obtidos em tabelas foram colocados em gráfico, e foi desenhada sua linha de tendência. A linha de tendência foi dada por uma Equação de primeiro grau, que irá proporcionar uma Equação 2 que associa o coeficiente de escoamento e a área impermeável, por meio do método:

$$
\left.\begin{array}{l}
C_{\text {bacia } 1}=a+b * A I_{\text {bacia } 1} \\
C_{\text {bacia } 2}=a+b * A I_{\text {bacia } 2}
\end{array}\right\} \text { encontrar elemento "a" } e^{"} b^{"}
$$

Depois, utilizou-se a área de um dos bairros, e sua população para obter a densidade habitacional (DH) em hab/ $\mathrm{km}^{2}$. Sabendo que existe uma relação entre densidade habitacional e área impermeável, considera-se a Equação 3, e tendo em mãos a porcentagem de área impermeável AI de uma bacia envolvendo o bairro específico e o DH desse bairro, é possível encontrar um coeficiente X que defina esta relação, e colocá-lo na equação do coeficiente de escoamento $\mathrm{C}$ das bacias. Daí será encontrada a relação entre o coeficiente de escoamento e a densidade habitacional. Esta relação possibilita calcular o C para uma densidade habitacional futura dos bairros de Campina Grande, e assim proporcionar os coeficientes usados nos cálculos da vazão de chuvas na cidade pelo método racional $\mathrm{Q}=$ C.i.a.

$$
\mathrm{AI}=\mathrm{X}^{*} \mathrm{DH}
$$

Onde AI é o percentual de área impermeável (\%) e DH a densidade habitacional $\left(\mathrm{hab} / \mathrm{km}^{2}\right)$.

\section{Resultados e Discussão}

O levantamento da classificação relativas as classes consideradas (Tabela 2) e relativas a bacia D3 está listado na Tabela 3. 
Research, Society and Development, v. 9, n. 7, e479974377, 2020

(CC BY 4.0) | ISSN 2525-3409 | DOI: http://dx.doi.org/10.33448/rsd-v9i7.4377

Tabela 3 - Dados referentes a bacia D3.

D3

RASTER MAP CATEGORY REPORT

LOCATION: temp_location

north: 7:13:00.197637S

REGION south: 7:13:40.253155S

res: 0:00:00.003275
Wed Nov 07 16:48:27 2018

east: $35: 52: 20.621222 \mathrm{~W}$

west: 35:53:09.990396W

res: 0:00:00.003275

Category Information

\begin{tabular}{|c|c|c|c|}
\hline$\#$ & Descrição & $\mathbf{k m}^{2}$ & ha \\
\hline 1 & Árvores e descampados & 1,095 & 109,509 \\
\hline 2 & Ruas asfaltadas e pavimentadas & 0,007 & 0,651 \\
\hline 3 & Casas, prédios e construções & 0,065 & 6,507 \\
\hline 4 & Ruas asfaltadas e pavimentadas & 0,004 & 0,419 \\
\hline 5 & Casas, prédios e construções & 0,092 & 9,176 \\
\hline 6 & Árvores e descampados & 0,000 & 0,000 \\
\hline 7 & Ruas asfaltadas e pavimentadas & 0,045 & 4,520 \\
\hline 8 & Árvores e descampados & 0,061 & 6,142 \\
\hline 9 & Ruas asfaltadas e pavimentadas & 0,000 & 0,000 \\
\hline 10 & Árvores e descampados & 0,005 & 0,460 \\
\hline 11 & Casas, prédios e construções & 0,003 & 0,307 \\
\hline 12 & Ruas asfaltadas e pavimentadas & 0,073 & 7,295 \\
\hline 13 & Árvores e descampados & 0,000 & 0,029 \\
\hline 14 & Casas, prédios e construções & 0,071 & 7,058 \\
\hline 15 & Árvores e descampados & 0,003 & 0,323 \\
\hline \multicolumn{2}{|r|}{ TOTAL } & 1,524 & 152,396 \\
\hline \multicolumn{2}{|r|}{ TOTAL DE ÁREA PERMEÁVEL (Ap) } & 0,149 & 14,911 \\
\hline \multicolumn{2}{|r|}{ TOTAL DE ÁREA IMPERMEÁVEL (Ai) } & 1,375 & 137,485 \\
\hline & 0,098 & $\mathrm{C}=$ & 0,823 \\
\hline
\end{tabular}

Fonte: Autores.

Da mesma forma foram efetuados os procedimentos para as outras bacias em estudo. No processamento de dados de algumas bacias foram detectados erros onde a classificação não pode levantar, com as amostras escolhidas, as áreas desejadas não sendo geradas 
Research, Society and Development, v. 9, n. 7, e479974377, 2020

(CC BY 4.0) | ISSN 2525-3409 | DOI: http://dx.doi.org/10.33448/rsd-v9i7.4377

conforme o esperado. Isto ocorreu para a bacia D3 e para as sub-classes 6 e 9.

A Tabela 4 demonstra a soma das áreas impermeável e permeável das bacias.

Tabela 4 - Resultado da classificação para as bacias em estudo.

\begin{tabular}{c|c|c|c|c|c}
\hline Bacia & $\begin{array}{c}\text { Arvores e } \\
\text { descampados }\end{array}$ & $\begin{array}{c}\text { Ruas asfaltadas e } \\
\text { pavimentadas }\end{array}$ & $\begin{array}{c}\text { Casas, prédios e } \\
\text { construções }\end{array}$ & Total permeável & Total impermeável \\
\hline D5 & 0,292 & 0,123 & 0,286 & 0,292 & 0,408 \\
\hline D7 & 0,814 & 0,299 & 0,158 & 0,814 & 0,458 \\
\hline D8 & 4,607 & 1,106 & 0,943 & 0,607 & 2,049 \\
\hline D4 & 0,547 & 0,024 & 0,534 & 0,547 & 0,558 \\
\hline D2 & 0,340 & 0,310 & 0,144 & 0,340 & 0,454 \\
\hline C8 & 0,255 & 0,317 & 0,273 & 0,255 & 0,240 \\
\hline C7 & 0,240 & 0,199 & 0,141 & 0,348 & 0,340 \\
\hline C6 & 0,348 & 0,152 & 0,200 & 0,417 & 0,353 \\
\hline C5 & 0,417 & 0,331 & 0,368 & 0,335 & 0,699 \\
\hline C4 & 0,335 & 0,217 & 0,229 & 0,447 \\
\hline B1 & 1,150 & 0,061 & 0,089 & 0,150 & 0,151 \\
\hline B5 & 0,643 & 0,213 & 0,172 & 0,643 & 0,385 \\
\hline D6 & 1,991 & 0,104 & 0,139 & 1,991 & 0,243 \\
\hline
\end{tabular}

Fonte: Autores.

A Tabela 5 apresenta a taxa de impermeabilidade (C) para cada bacia, assim como os valores das porcentagens de área impermeável (AI), a partir dos valores de áreas obtidos.

Tabela 5 - Valores de C e AI de cada bacia.

\begin{tabular}{c|c|c|c}
\hline Bacia & Área da bacia $\left(\mathbf{k m}^{\mathbf{2}}\right)$ & $\mathbf{A I}(\boldsymbol{\%})$ & $\mathbf{C}$ \\
\hline D8 & 6,656 & 30,78 & 0,51 \\
\hline D7 & 1,274 & 36,0 & 0,54 \\
\hline D5 & 0,701 & 58,33 & 0,51 \\
\hline D4 & 1,105 & 50,49 & 0,50 \\
\hline C2 & 0,790 & 57,21 & 0,51 \\
\hline C7 & 0,847 & 69,81 & 0,56 \\
C6 & 0,580 & 58,63 & 0,50 \\
\hline C5 & 0,702 & 50,34 & 0,53 \\
\hline C4 & 1,118 & 62,59 & 0,51 \\
\hline C2 & 0,783 & 57,12 & 0,79 \\
\hline B5 & 1,523 & 11,58 & 0,53 \\
\hline D6 & 2,519 & 37,41 & 0,80 \\
\hline
\end{tabular}

Fonte: Autores.

É de extrema importância ressaltar que houve valores de coeficientes de escoamento que não condizem com os coeficientes de escoamento reais. Um exemplo disso é a bacia C2, que envolve os bairros Jardim Continental, Alto Branco e Nações, regiões afastadas do centro e ainda com diversas áreas permeáveis. De acordo com Tabela 5, seu coeficiente de escoamento foi alto, de 0,79 , o que não condiz com o escoamento desses bairros. $\mathrm{O}$ mesmo caso se pode verificar em relação a bacia D4, que envolve os bairros de Centro e José 
Pinheiro, que obtiveram um coeficiente de 0,5, entretanto esses bairros possuem muitas construções e ruas pavimentadas ou asfaltadas, o que deveria aumentar o coeficiente de escoamento.

Espera-se em gráficos de C x AI que, para áreas de baixa porcentagem de área impermeável, encontram-se baixos valores de C, e não foi o que aconteceu com as bacias, C2, B5 e D6. Isso pode se dever ao fato que para o arquivo classificado no QGis, algumas áreas não puderam ser aferidas corretamente, pois, devido a sombras ou posições diferentes do sol, alguns pixels tiveram suas colorações alteradas, sendo considerados de classes diferentes de sua classe correta. Gerando, assim, um valor errado de permeabilidade. A Figura 3 apresenta o gráfico C x AI sem os valores não condizentes, a fim de uma melhor aferição, encontrando a linha de tendência conforme demonstrado.

Figura 3 - Coeficiente de escoamento em função da área impermeável.

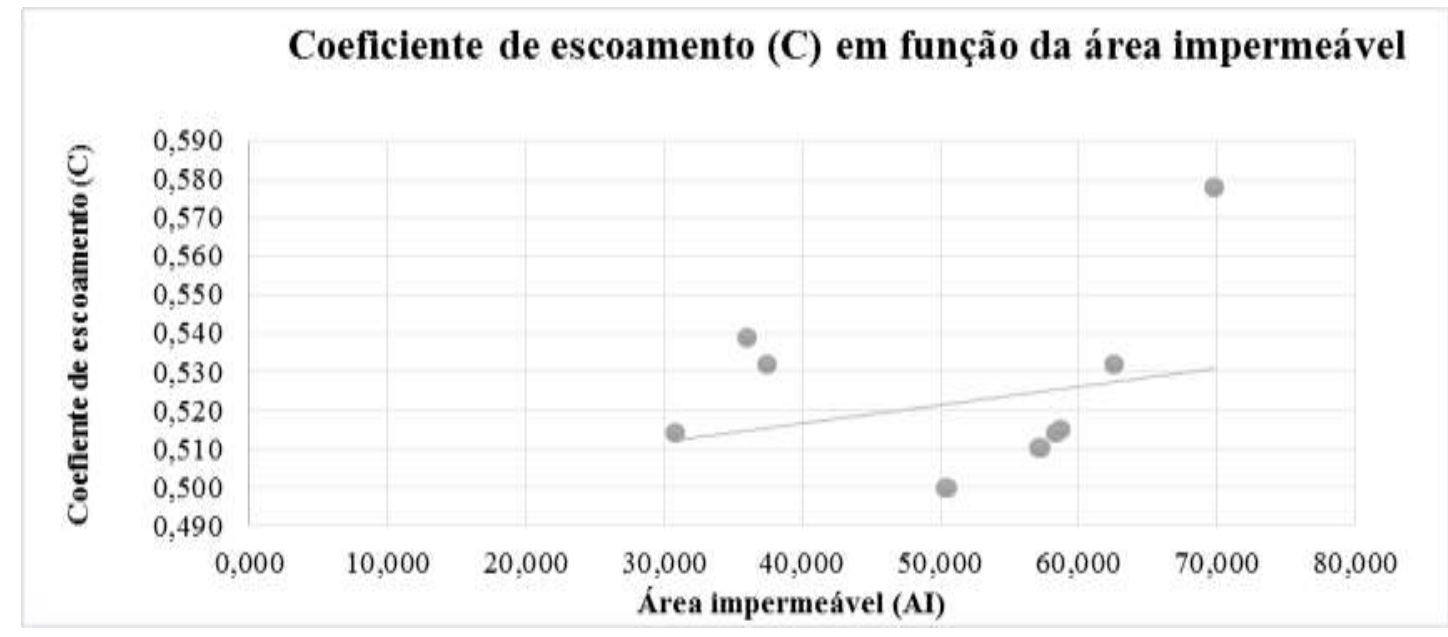

Fonte: Autores.

Diante dos locais onde passa a linha de tendência, encontraram-se os valores: $\mathrm{C}=$ 0,517 para $\mathrm{AI}=40$ e $\mathrm{C}=0,562$ para $\mathrm{AI}=60$.

Utilizando a Equação 2 do item de metodologias foi encontrado o valor de "a" e "b":

$$
\left\{\begin{array}{l}
0,517=a+40 b \\
0,526=a+60 b
\end{array} \rightarrow a=0,5 ; b=0,00045\right.
$$

Desse modo, a Equação do Coeficiente de escoamento em função da porcentagem de área impermeável será dada por:

$$
C=0,5+0,00045 * A I
$$


Research, Society and Development, v. 9, n. 7, e479974377, 2020

(CC BY 4.0) | ISSN 2525-3409 | DOI: http://dx.doi.org/10.33448/rsd-v9i7.4377

A Tabela 6 apresenta os resultados das áreas dos bairros por meio do software QGis, e suas populações, em habitantes por bairro, obtido por meio do IBGE.

Tabela 6 - Densidade habitacional de 18 bairros de Campina Grande.

\begin{tabular}{|c|c|c|c|}
\hline & há & hab por bairro & DH em hab/há \\
\hline Liberdade & 153,762 & 11821 & 76,88 \\
\hline Jardim paulistano & 118,732 & 1090 & 9,18 \\
\hline Tambor & 131,628 & 3879 & 29,47 \\
\hline Catolé & 295,946 & 12683 & 42,86 \\
\hline Itararé & 93,820 & 1708 & 18,21 \\
\hline Sandra Cavalcante & 134,024 & 5157 & 38,48 \\
\hline Vila Cabral & 100,869 & 1254 & 12,43 \\
\hline José Pinheiro & 124,954 & 10936 & 87,52 \\
\hline Centro & 203,802 & 6016 & 29,52 \\
\hline Prata & 78,940 & 3573 & 45,26 \\
\hline Bela Vista & 72,736 & 3630 & 49,91 \\
\hline Monte Santo & 84,441 & 880 & 10,42 \\
\hline Monte Castelo & 90,047 & 485 & 5,39 \\
\hline Jardim Tavares & 233,677 & 993 & 4,25 \\
\hline Palmeira & 84,476 & 939 & 11,12 \\
\hline Centenário & 82,991 & 1895 & 22,83 \\
\hline Quarenta & 55,259 & 4259 & 77,07 \\
\hline Estação velha & 46,400 & 4145 & 89,33 \\
\hline São José & 60,544 & 3950 & 65,24 \\
\hline
\end{tabular}

Fonte: Autores.

Dos bairros listados, foi utilizado os dados do bairro do Catolé, com 42,86 hab/ha, e relacionado ás bacias D5, D7, D8, que são as bacias que envolvem o bairro. Sendo a porcentagem de área impermeável (AI) de cada bacia, e considerando $\mathrm{AI}=\mathrm{X} * \mathrm{DH}$, temos:

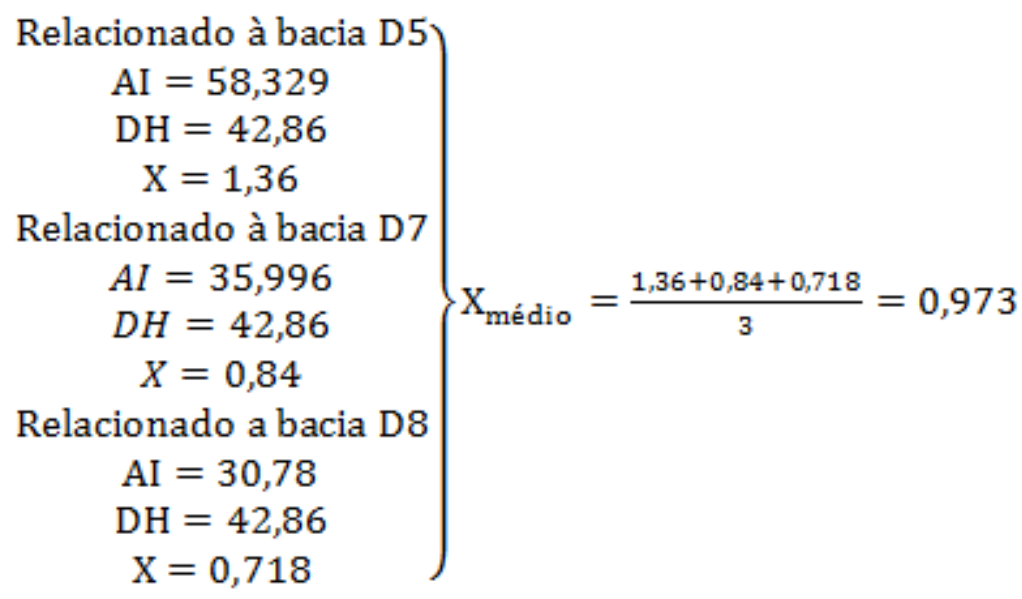

Desse modo, a relação entre AI e DH foi dada pela Equação 6:

$$
A I=0,973 \cdot D H
$$

Vale constar que o coeficiente $\mathrm{X}$, que associa os valores de área impermeável e densidade habitacional, apenas poderá ser usado para bairros semelhantes ao bairro utilizado 
para encontrar o coeficiente. Isso se deve ao fato que, para bairros idênticos, haverá valores equivalentes de densidade habitacional e impermeabilidade entre eles. Como o valor médio de $\mathrm{X}$ acima calculado foi utilizando o bairro Catolé, apenas poderão ser usados bairros idênticos, com o mesmo tipo de crescimento.

E, finalmente, relacionando a Equação 3 com a Equação 5 teremos os valores de C dados por meio da seguinte Equação:

$$
C=0,5-0,00044 . D H
$$

Tendo em mãos a Equação 6, será possível calcular o coeficiente de escoamento de um bairro que tenha a tendência de desenvolvimento habitacional igual ao do bairro Catolé. $\mathrm{E}$ com o coeficiente de escoamento, a área da bacia em $\mathrm{km}^{2}$ e a intensidade da precipitação em $\mathrm{mm} / \mathrm{h}$, será possível calcular a vazão máxima, em m³/s, pela Equação do método racional (item 3.3):

$$
Q=C \cdot i \cdot A
$$

A vazão encontrada pode ser aplicada, por exemplo, no dimensionamento de redes de drenagem urbana, além de dar conhecimento acerca da velocidade de escoamento nas regiões de alta declividade, onde serão aplicados os coeficientes de escoamento, podendo assim definir os locais onde existe risco de enxurradas.

Ainda é possível, de acordo com a vazão encontrada, indicar o volume de água para uma determinada chuva e área de alta densidade populacional, e, tendo conhecimento da capacidade de captação dos canais de drenagem da cidade, é possível indicar se haverá riscos de inundações para essa chuva ou não. Desse modo será possível evitar grandes prejuízos à população que se encontram nas várzeas dos pontos de deságua.

Diante dos coeficientes encontrados ainda é possível fazer comparações com os coeficientes de escoamento encontrados anteriormente. Para o caso da bacia D4, encontrada na figura 4, envolvendo os bairros do centro e José Pinheiro, foi calculado, de acordo com a classificação feita, um coeficiente de escoamento de 0,5. Reconhecendo essa bacia como área comercial/edificação muito densa, seu coeficiente deveria variar, de acordo com a Figura 4, entre 0,7 e 0,95. Esse erro pode ser causado tanto pela nuvem, encontrada na imagem, como pela região do Açude, que pode ter sido confundido com a vegetação, uma vez que possui a cor mais esverdeada. 
Research, Society and Development, v. 9, n. 7, e479974377, 2020

(CC BY 4.0) | ISSN 2525-3409 | DOI: http://dx.doi.org/10.33448/rsd-v9i7.4377

Na bacia D7, envolvendo os bairros de Sandra Cavalcante, Catolé e Vila Cabral, que pode ser considerado, de acordo com a Figura 4, uma área residencial envolvendo partes residenciais com ruas pavimentadas, com coeficiente entre 0,5 e 0,6. De acordo com a Tabela 5 , o coeficiente de escoamento da bacia será de 0,54 , estando dentro dos padrões assinalados.

Figura 4 - Valores de C por tipo de ocupação.

\begin{tabular}{|c|c|}
\hline Descrição da área & C \\
\hline \multicolumn{2}{|l|}{ Área Comercial/Edificação Muito densa: } \\
\hline $\begin{array}{l}\text { Partes centrais, densamente construidas, em cidade com ruas e calçadas } \\
\text { pavimentadas }\end{array}$ & $0,70-0,95$ \\
\hline \multicolumn{2}{|l|}{ Área Comercial/Edificação não muito densa: } \\
\hline $\begin{array}{l}\text { Partes adjacentes ao centro, de menor densidade de habitaçōes, mas com } \\
\text { ruas e calçadas pavimentadas }\end{array}$ & $0,60-0,70$ \\
\hline \multicolumn{2}{|l|}{ Área Residencial: } \\
\hline residencias isoladas; com muita superfície livre & $0,35-0,50$ \\
\hline $\begin{array}{l}\text { unidades múltiplas (separadas); partes residenciais com ruas } \\
\text { macadamizas ou pavimentadas }\end{array}$ & $0,50-0,60$ \\
\hline unidades múltiplas (conjugadas) & $0,60-0,75$ \\
\hline lotes $\mathrm{com}>2.000 \mathrm{~m}^{2}$ & $0,30-0,45$ \\
\hline âreas com apartamentos & $0,50-0,70$ \\
\hline \multicolumn{2}{|l|}{ Área industrial: } \\
\hline indústrias leves & $0,50-0,80$ \\
\hline indústrias pesadas & $0,60-0,90$ \\
\hline \multicolumn{2}{|l|}{ Outros: } \\
\hline $\begin{array}{l}\text { Matas, parques e campos de esporte, partes rurais, áreas verdes, } \\
\text { superfícies arborizadas e parques ajardinados }\end{array}$ & $0,05-0,20$ \\
\hline parques, cemiterios; subúrbio com pequena densidade de construcăo & $0,10-0,25$ \\
\hline Playgrounds & $0,20-0,35$ \\
\hline pátios ferroviários & $0,20-0,40$ \\
\hline áreas sem melhoramentos & $0,10-0,30$ \\
\hline
\end{tabular}

Fonte: Adaptado de ASCE (1969) e Wilken (1978).

Usando como exemplo um bairro de densidade habitacional em torno de 50 hab/ha, e inserindo esse valor na Equação 7, obtém-se um Coeficiente de Escoamento (C) de 0,522. Considerando ser um bairro com descrições idênticas ao Catolé, com partes residenciais e ruas pavimentadas, seu coeficiente estaria dentro do intervalo estabelecido na Figura 4.

As inconsistências encontradas nesse trabalho podem ocorrer por erro pessoal na escolha das amostras coletadas, pela má aferição dos pixels, classificando como região permeável as que deveriam ser permeáveis e pelo fato deste trabalho lidar com uma composição de imagens. Quando se trata de uma composição, as imagens podem ter sido tratadas anteriormente. Essa alteração implica numa classificação menos eficaz, podendo tornar o processo impreciso.

\section{Considerações Finais}

Os resultados obtidos das equações 3 e 6, envolvendo o coeficiente de escoamento e densidade habitacional, foram consideradas de boa representatividade para o presente trabalho 
em relação a densidade habitacional do Bairro Catolé, entretanto é necessária devida atenção em relação a bairros de comércio, como o centro, pois o valor do coeficiente encontrado não se coincidiu com os padrões para regiões de área comercial e edificação alta densidade.

Porém, é importante lembrar que existiram casos em que não ocorreu uma boa aferição do software. Desse modo, os resultados dos tamanhos das áreas permeáveis ou impermeáveis poderão se apresentar diferentes da real situação da região, alterando, assim, o índice de permeabilidade, a área impermeável e até a área total da imagem em questão. Vale constar que, para trabalhos futuros, as imagens utilizadas sejam recentes e de boa qualidade para melhor definição dos fatores procurados.

Deve ser observado, também, que os valores estimados de impermeabilização do solo em relação a bairros idênticos ao aferido, foram condizentes com os valores utilizados para o coeficiente de escoamento, da Figura 4. Representando certo amparo em relação à certeza dos graus de impermeabilização encontrados para bairros residenciais com ruas pavimentadas.

Ainda foi possível identificar a utilidade de se obter o coeficiente de escoamento, relacionando-o com situações de enxurradas, enchentes e inundações recorrentes em cidades de alto grau de impermeabilização.

Por fim, pode-se concluir que o software QGis é de grande utilidade para as estimativas relacionadas a drenagem urbana e suas bacias. Entretanto é necessário cautela em relação a seus resultados, uma vez que determinadas regiões podem ser aferidas incorretamente. E, ainda é possível avaliar que existe uma conexão equacional entre densidade habitacional e coeficiente de escoamento, ou grau de impermeabilização, e essa conexão pode ser utilizada em situações futuras, envolvendo o crescimento habitacional de um bairro, tanto na cidade de Campina Grande como em outras cidades que se utilizem da mesma metodologia que a deste trabalho.

\section{Referências}

Aragão, R et al. (2017) Impacto do uso do solo pelo aumento da densidade populacional sobre o escoamento numa área urbana do Nordeste Brasileiro via geotecnologias e modelagem hidrológica. Revista Brasileira de Geografia Física 10(2), 543-557.

ASCE. (1969) Design and construction of sanitary and storm sewers. Manuals and Reports of Engineering Pratice $N^{o} 37$. New York. 
Canholi, AP. (2015) Drenagem Urbana e Controle de Enchentes. São Paulo, Ed. Oficina de Textos, 2015.

Franco, EJ. (2004) Dimensionamento de bacias de detenção das águas pluviais com base no método racional. 155 f. Dissertação (Mestrado em Engenharia de Recursos Hídricos e Ambiental) - Universidade Federal do Paraná, Curitiba.

Instituto Brasileiro de Geográfia e Estatística. (2018). Acesso em dezembro de 2018 em http:www.ibge.gov.br. IBGE.

Instituto de Desenvolvimento Estadual e Municipal da Paraíba. (2018). Acesso em outubro de 2018 em http://ideme.pb.gov.br/. IDEME.

Rufino, IAA. (2015) Estimativa de taxas de impermeabilização do solo das bacias urbanas do município de Campina Grande - PB utilizando sensoriamento remoto. In: XVII Simpósio Brasileiro de Sensoriamento Remoto. João Pessoa.

Secretaria de Planejamento, Gestão e Transparência de Campina Grande. (2018) Acesso em novembro de 2018 em https://campinagrande.pb.gov.br/secretarias/planejamento/. SEPLAN.

Souza, ES, Antonino, ACD, Ângulo-jaramillo, R, Netto, AM. (2008) Caracterização hidrodinâmica de solos: Aplicação do método Beerkan. Revista Brasileira de Engenharia Agrícola e Ambiental 12, 128-35.

Tsuyuguchi, BB. (2015) Macrodrenagem e ocupação do solo no município de Campina Grande: caracterização, simulação e análises sistêmicas. 102 f. Dissertação (Mestrado em Engenharia Civil e Ambiental) - Universidade Federal de Campina Grande, Campina Grande.

Tucci, CEM. (2007) Plano Diretor de Drenagem Urbana: Princípios e Concepção. Revista Brasileira de Recursos Hídricos 2(2), 5-12.

Wilken, PS. (1978) Estruturas hidráulicas singulares. In: Engenharia de drenagem superficial. São Paulo: Companhia de Tecnologia de Saneamento Ambiental. CETESB. 
Research, Society and Development, v. 9, n. 7, e479974377, 2020

(CC BY 4.0) | ISSN 2525-3409 | DOI: http://dx.doi.org/10.33448/rsd-v9i7.4377

Porcentagem de contribuição de cada autor no manuscrito

Debora Rodrigues Soares $-25 \%$

Osires de Medeiros Melo Neto - 25\%

Gustavo Correia Basto da Silva - 25\%

Ricardo de Aragão - 25\% 